\title{
Clinical utility of HER2 assessed by immunohistochemistry in patients undergoing curative resection for gastric cancer
}

\author{
Xuechao Liu',2,* \\ Pengfei $\mathrm{Xu}^{1,3, *}$ \\ Haibo Qiu ${ }^{1,2, *}$ \\ Jianjun Liu',2 \\ Shangxiang Chen ${ }^{1,2}$ \\ Dazhi $X u^{1,2}$ \\ Wei $\mathrm{Li}^{1,2}$ \\ Youqing Zhan ${ }^{1,2}$ \\ Yuanfang $\mathrm{Li}^{1,2}$ \\ Yingbo Chen ${ }^{1,2}$ \\ Zhiwei Zhou ${ }^{1,2}$ \\ Xiaowei Sun ${ }^{1,2}$
}

'Sun Yat-sen University Cancer Center, State Key Laboratory of Oncology in South China, Collaborative Innovation Center for Cancer Medicine, ${ }^{2}$ Department of Gastric and Pancreatic Surgery, ${ }^{3}$ Department of Thoracic Surgery, Sun Yat-sen University Cancer Center, Guangzhou, People's Republic of China

*These authors contributed equally to this work

Correspondence: Xiaowei Sun Department of Gastric and Pancreatic Surgery, Sun Yat-sen University Cancer Center, 65 I\# East Dongfeng Road, Guangzhou 510060, Guangdong, People's Republic of China Fax +862087343123 Email sunxw@sysucc.org.cn
This article was published in the following Dove Press journal:

OncoTargets and Therapy

26 February 2016

Number of times this article has been viewed

Purpose: We sought to determine whether human epidermal growth factor receptor 2 (HER2) and vascular endothelial growth factor (VEGF) expression were independent prognostic factors for gastric cancer (GC).

Patients and methods: A total of 678 consecutive patients with GC undergoing curative surgery between October 2010 and December 2012 had resected tissue examined for HER2 and VEGF expression using immunohistochemistry. Immunohistochemical expression of HER2 was analyzed using the DAKO-HercepTest ${ }^{\mathrm{TM}}$ and scored according to published reports. VEGF expression was calculated by multiplying the score for the percentage of positive cells by the intensity score. We defined positive expression as a score of $1+, 2+$, or $3+$, and a score of 0 was defined as negative expression. We compared these results to clinicopathological characteristics, including overall survival (OS).

Results: Multivariate analysis revealed that HER2 expression was independently associated with shorter OS (hazard ratio [HR], 1.55; 95\% confidence interval [CI], 1.10-2.18; $P=0.01$ ) and with higher tumor-nodes-metastasis stage (HR, 3.88; 95\% CI, 2.67-5.64; $P<0.001$ ) in patients with GC. VEGF expression was not associated with OS (HR, 1.25; 95\% CI, 0.86-1.82; $P=0.24$ ). HER2 expression was still identified as an independent prognostic factor in Stage II-III patients treated with surgery and adjuvant chemotherapy $(P=0.004)$ but not in patients who received surgery alone $(P=0.61)$. Among patients with Stage III GC, those without HER2 expression survived longer with adjuvant chemotherapy (median 43.9 vs 32.2 months, respectively; $P=0.04$ ), whereas those with HER2 expression did not (median 37.1 vs 33.9 months, respectively; $P=0.67$ ).

Conclusion: HER2 expression is independently associated with OS in GC, especially in patients who are at higher risk and receive adjuvant chemotherapy after curative resection. HER2 expression may have important clinical utility in directing adjuvant treatment for Stage III GC patients.

Keywords: adjuvant chemotherapy, human epidermal growth factor receptor 2, prognosis, vascular endothelial growth factor, VEGF

\section{Introduction}

Gastric cancer (GC) is the fourth most commonly diagnosed cancer and the second leading cause of cancer-related deaths worldwide., ${ }^{1,2}$ Despite advances in surgical techniques and multidisciplinary treatment, the long-term survival of postoperative patients still remains unsatisfactory, particularly for those with higher stage GC. ${ }^{3}$

In many cancers, independent prognostic factors are useful in selecting highrisk patients and tailoring treatment. Up to now, the tumor-nodes-metastasis (TNM) system has been the gold standard for assessing GC prognosis. However, 
in this system, prognosis varies among patients with the same stage. Therefore, investigators have sought other prognostic factors that might help improve the clinical management of GC.

One candidate is human epidermal growth factor receptor 2 (HER2), a transmembrane tyrosine kinase receptor. The measurement of HER2 expression has become a valuable prognostic tool for use in the management of breast cancer. ${ }^{4}$ However, the results of studies of the possible prognostic role of HER2 expression in GC have been conflicting: some have shown no prognostic value, while others have shown an association between HER2 expression and poorer survival. ${ }^{5-10}$ Vascular endothelial growth factor (VEGF) is another marker with potential prognostic value, although studies involving VEGF expression and GC have also yielded mixed results. ${ }^{11}$

We performed a retrospective laboratory study to determine whether HER2 and VEGF expression were independent prognostic factors for GC. Our goal was to measure HER2 and VEGF expression in our GC patients and to compare these results to a variety of clinicopathological variables, including overall survival (OS). We opted to use immunohistochemistry (IHC) to measure expression because it is less expensive and more practical than fluorescence in situ hybridization (FISH).

\section{Material and methods}

The study was approved by the Research Ethics Committee of Sun Yat-sen University Cancer Center, People's Republic of China, and was performed in accordance with the ethical standards of the World Medical Association's Declaration of Helsinki. Written informed consent was obtained from each patient.

\section{Study population}

This retrospective laboratory study involved consecutive patients who underwent curative surgery for GC at Sun Yat-sen University Cancer Center between October 2010 and December 2012.

Patients who met all the following criteria were included in the study: 1) no neoadjuvant chemotherapy or radiotherapy, 2) no other synchronous malignancy, 3) adequate paraffin-embedded tumor tissue sample for HER2 and VEGF analysis, and 4) complete set of clinicopathological and follow-up data. No patients received trastuzumab, even after cancer recurrence.

The clinicopathological characteristics of all patients were retrieved from our hospital information system.
All patients had histologically confirmed Stage I-III gastric adenocarcinoma according to the seventh edition of the American Joint Committee on Cancer TNM staging system. ${ }^{12}$ Patients with Stage III or high-risk Stage II GC and no marked comorbidities precluding chemotherapy were offered 5-fluorouracil-based adjuvant chemotherapy after surgery, in accordance with current clinical guidelines. ${ }^{13-15}$

\section{Immunohistochemistry}

The levels of HER2 and VEGF protein expression were measured by IHC. Representative $4 \mu \mathrm{m}$ thick tissue sections were cut from the paraffin-embedded tumor blocks to use for IHC analysis. Staining was carried out using a primary polyclonal rabbit antibody (DAKO, Glostrup, Denmark) against HER2 and VEGF, respectively, on a Ventana Benchmark XT automated staining instrument (Ventana Medical Systems, Tucson, AZ, USA), according to the manufacturer's instructions.

HER2 immunohistochemical expression was analyzed using the DAKO HercepTest ${ }^{\mathrm{TM}}$ and according to the American Society of Clinical Oncology - College of American Pathologists guidelines for the assessment of HER2 expression. The amended HER2 IHC scoring system for GC proposed by Bang et al was used: a score of 0 meant no reactivity, or membranous reactivity in less than $10 \%$ of tumor cells; a score of $1+$ meant faint or barely perceptible membranous reactivity in $10 \%$ or more of tumor cells or that cells exhibited incomplete membrane reactivity; a score of $2+$ indicated weak-to-moderate complete basolateral or lateral membranous reactivity in at least $10 \%$ of tumor cells; and a score of $3+$ indicated strong complete basolateral or lateral membranous reactivity in $10 \%$ or more of tumor cells. ${ }^{16}$ Using these data, we condensed the results for HER2 expression further, defining them as either negative (score 0 ) or positive (score $1+, 2+$, and $3+$ ), consistent with the classification methods reported in other studies. ${ }^{5,17,18}$

VEGF immunohistochemical expression was scored based on the following criteria: percentage of positive tumor cells in the tumor tissue $(0[<5 \%], 1[5 \%-25 \%], 2$ [26\%-50\%], $3[>50 \%])$ and signal intensity (0 [no staining], 1 [weak staining], 2 [moderate staining], or 3 [strong staining]). The final score was calculated by multiplying the score for the percentage of positive cells by the intensity score (score 0: range $0-1$; score $1+$ : range $1-3$; score $2+$ : range $4-6$; and score 3+: range 7-9). The results were condensed in the same way, defining them as either negative (score 0 ) or positive (score 1+, 2+, and 3+). 


\section{Follow-up}

Patients were followed clinically every 3 months during the first 2 years after surgery and every 6 months thereafter. At each follow-up visit, patients had laboratory testing (including baseline concentrations of serum tumor markers), a dynamic abdominal computed tomography scan, and gastroscopy. The final follow-up date for the study was June 25, 2015. We calculated OS as the time from the date of surgery to the date of either death or last follow-up.

\section{Statistical methods}

Results are presented as mean with $95 \%$ confidence intervals (CI). Differences among groups were analyzed using Pearson's chi-squared test or Fisher's exact test for qualitative variables. Survival analysis was carried out using the Kaplan-Meier method, and differences between survival curves were determined using a log-rank test. Variables significant $(P<0.05)$ in the univariate or unadjusted analysis were selected for inclusion in a final multivariate Cox proportional hazards model, entering all variables in a single step. All statistical analyses were conducted using the IBM SPSS Statistics for Windows, Version 19.0 (IBM Corporation, Armonk, NY, USA). Alpha was set at 0.05, and all tests were two-tailed.

\section{Results}

Of the 678 patients included in the study, 454 were male and 224 were female. The median age of patients at the time of diagnosis was 59 years (range, 18-84 years). Of these, 353 (52.1\%) patients had Stage III GC. The median follow-up period was 33 months (range 1-59 months). During the follow-up period, 159 (23.5\%) patients died, and $519(76.5 \%)$ were alive at last follow-up (Table 1).

On the basis of our condensed classification method for HER2 expression, 405 (59.7\%) patients were considered negative and 273 (40.3\%) patients were considered positive for HER2 expression.

Patients with HER2 expression had significantly shorter OS than those without HER2 expression (median 43.5 vs 49.3 months, respectively; $P=0.03$; Figure 1 ).

HER2 expression was associated with male sex $(P=0.04)$, tumor location (upper third of stomach; $P<0.001$ ), welldifferentiated histology $(P<0.001)$, intestinal-type pathology $(P=0.004)$, and VEGF expression $(P=0.008$; Table 2$)$.

Our univariate analysis showed that tumor location, tumor size, TNM stage, carcinoembryonic antigen, carbohydrate antigen 19-9, VEGF expression, and HER2 expression were all associated with OS. However, on multivariate analysis,
Table I Clinical and laboratory characteristics of 678 patients with GC

\begin{tabular}{|c|c|}
\hline Characteristic & Patients, n (\%) \\
\hline \multicolumn{2}{|l|}{ Age, years } \\
\hline$<60$ & $355(52.4)$ \\
\hline$\geq 60$ & $323(47.6)$ \\
\hline \multicolumn{2}{|l|}{ Sex } \\
\hline Male & $454(67.0)$ \\
\hline Female & $224(33.0)$ \\
\hline \multicolumn{2}{|l|}{ Tumor location } \\
\hline Upper third & $215(31.7)$ \\
\hline Middle third & $170(25.1)$ \\
\hline Lower third & $293(43.2)$ \\
\hline \multicolumn{2}{|l|}{ Tumor size, cm } \\
\hline$<5$ & $455(67.1)$ \\
\hline$\geq 5$ & $223(32.9)$ \\
\hline \multicolumn{2}{|l|}{ Histological grade } \\
\hline Well-differentiated & $132(19.5)$ \\
\hline Poorly differentiated & $546(80.5)$ \\
\hline \multicolumn{2}{|l|}{ Histological type } \\
\hline Intestinal type & |48 (2I.8) \\
\hline Diffuse type & $250(36.9)$ \\
\hline Mixed type & $76(11.2)$ \\
\hline \multicolumn{2}{|l|}{ TNM stage } \\
\hline 1 & 135 (19.9) \\
\hline II & $190(28.0)$ \\
\hline III & $353(52.1)$ \\
\hline \multicolumn{2}{|l|}{ Adjuvant chemotherapy } \\
\hline Yes & $503(74.2)$ \\
\hline No & $175(25.8)$ \\
\hline \multicolumn{2}{|l|}{ CEA } \\
\hline Normal & $482(7 \mid . I)$ \\
\hline Elevated & $503(19.2)$ \\
\hline \multicolumn{2}{|l|}{ CAI9-9 } \\
\hline Normal & $511(75.4)$ \\
\hline Elevated & $74(10.9)$ \\
\hline \multicolumn{2}{|l|}{ CA72-4 } \\
\hline Normal & $470(69.3)$ \\
\hline Elevated & $|2|(\mid 7.8)$ \\
\hline \multicolumn{2}{|l|}{ VEGF expression } \\
\hline Positive & $439(64.7)$ \\
\hline Negative & $239(35.3)$ \\
\hline \multicolumn{2}{|l|}{ HER2 expression } \\
\hline Positive & $273(40.3)$ \\
\hline Negative & $405(59.7)$ \\
\hline
\end{tabular}

Abbreviations: CA, carbohydrate antigen; CEA, carcinoembryonic antigen; GC, gastric cancer; HER2, human epidermal growth factor receptor 2; TNM, tumor-node-metastasis; VEGF, vascular endothelial growth factor.

only HER2 expression (hazard ratio [HR], 1.55; 95\% CI, $1.10-2.18 ; P=0.01)$ and TNM stage (HR, 3.88; 95\% CI, 2.67-5.64; $P<0.001)$ were independently associated with OS. VEGF expression was not associated with OS (HR, 1.25; 95\% CI, 0.86-1.82; $P=0.24$; Table 3).

When we stratified our patients into two groups, those treated with surgery plus adjuvant chemotherapy and those treated with surgery alone, we found that HER2 


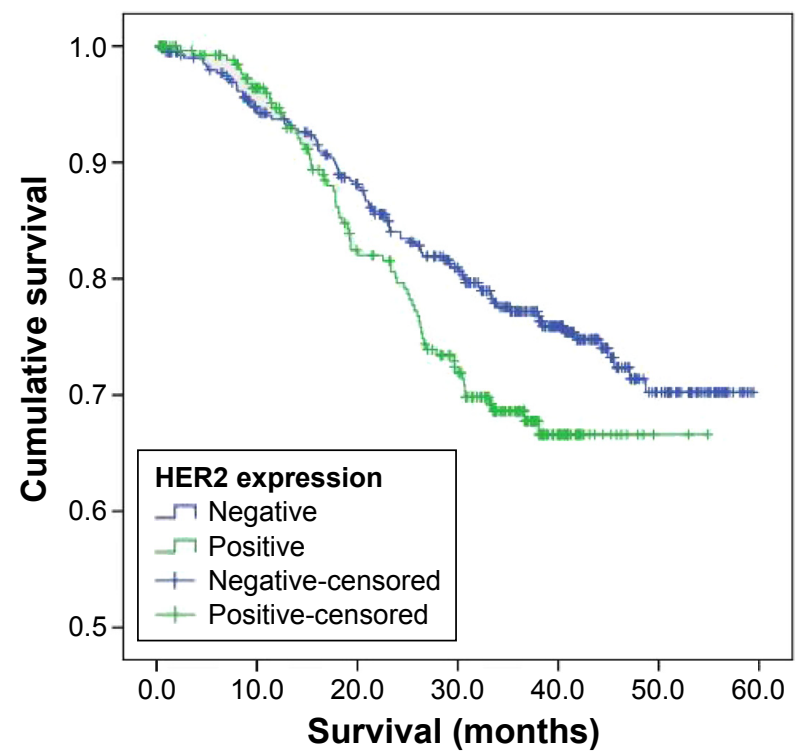

Figure I OS of patients with GC based on HER2 immunohistochemical expression.

Abbreviations: OS, overall survival; GC, gastric cancer; HER2, human epidermal growth factor receptor 2 .

expression was associated with shorter OS in those receiving chemotherapy $(P=0.004)$, but HER2 expression was not associated with OS in those who had surgery without chemotherapy ( $P=0.61$; Table 4 and Figure 2).

In Stage III GC patients without HER2 expression, OS was longer in those who received surgery plus adjuvant chemotherapy than in those who received only surgery (median 43.9 vs 32.2 months, respectively; $P=0.04$ ). However, in Stage III GC patients with HER2 expression, there was no significant difference in OS between those receiving surgery with adjuvant chemotherapy and those receiving surgery alone (median 37.1 vs 33.9 months, respectively; $P=0.67$; Figure 3).

\section{Discussion}

The promising results from the trastuzumab for gastric cancer (ToGA) trial have resulted in renewed interest in the relationship between HER2 overexpression, gastric tumor biology, and prognosis. ${ }^{16}$ Trastuzumab is a monoclonal antibody that interferes with the HER2 receptor, and so cells that overexpress this receptor may be more susceptible to this medication. In breast cancer, HER2 overexpression has been an important prognostic factor for the response to trastuzumab therapy, and overexpression of HER2 has been associated with poor outcomes, high recurrence rates, and metastasis. ${ }^{19}$ However, in GC, the relationship between HER2 overexpression and prognosis remains less clear. ${ }^{20-24}$ We sought to clarify this relationship by retrospectively measuring
HER2 expression in our GC patients and comparing the results to a variety of other clinicopathological variables, including OS.

In our study, we found that those GC patients with HER2 expression had significantly shorter OS than those without HER2 expression. We also observed that OS in GC was independently associated with only two of our variables: HER2 expression and TNM stage. In addition, HER2 expression was associated with male sex, tumor location in the upper third of the stomach, well-differentiated histology, intestinal-type pathology, and VEGF expression.

The literature regarding the relationship between HER2 expression and GC prognosis has been inconclusive. One meta-analysis of 19 studies suggested that HER2 overexpression in $\mathrm{GC}$ was associated with poor prognosis. Using univariate analysis, 15 of the studies showed an association between HER 2 expression and shorter survival; however, using multivariate analysis, only seven of those studies reported that HER2 expression was an independent negative prognostic factor for GC. ${ }^{25}$ Another recent systematic review reporting on the impact of HER2 overexpression on survival in GC included 13 studies that found shorter OS in patients with HER2 overexpression, 20 studies that reported no difference in overall OS, and two studies that observed longer OS in patients with HER2 overexpression. ${ }^{26}$

Smaller research studies have also explored the relationship between HER 2 expression and prognosis. One recent study, which used a more stringent definition of HER 2 overexpression than we did, showed that HER2 overexpression was not associated with disease-specific or recurrence-free survival in $\mathrm{GC}^{27} \mathrm{Xu}$ et $\mathrm{al}^{28}$ reported that HER2, as a predictor of long-term survival, was limited; however, their multivariate analysis revealed that HER2 expression was independently associated with GC recurrence. Finally, a study from our center found that HER2 expression was not an independent prognostic factor for the entire group of GC patients; however, it was prognostic for the subset of GC patients with intestinal-type pathology and TNM Stages I or II. In addition, the authors concluded that patients with intestinal-type pathology and without HER2 expression had the best survival, and patients with diffuse-type pathology and HER2 expression had the worst. ${ }^{29}$ Thus, despite the inconclusive nature of the literature on this subject, our study, which found that HER2 expression was independently associated with OS in GC, adds to the evidence that HER2 expression is a prognostic factor for GC. The difference between our results and those in some other studies could 
Table 2 Differences in HER2 expression, by clinicopathologic characteristic

\begin{tabular}{|c|c|c|c|}
\hline Characteristic & $\begin{array}{l}\text { HER2 expression negative } \\
(n=405)\end{array}$ & $\begin{array}{l}\text { HER2 expression positive } \\
(n=273)\end{array}$ & $P$-value \\
\hline Age, years & & & 0.16 \\
\hline$<60$ & 221 & 134 & \\
\hline$\geq 60$ & 184 & 139 & \\
\hline Sex & & & 0.04 \\
\hline Male & 259 & 195 & \\
\hline Female & 146 & 78 & \\
\hline Tumor location & & & 0.001 \\
\hline Upper third & 107 & 108 & \\
\hline Middle third & 108 & 62 & \\
\hline Lower third & 190 & 103 & \\
\hline Tumor size, cm & & & 0.63 \\
\hline$<5$ & 275 & 179 & \\
\hline$\geq 5$ & 130 & 94 & \\
\hline Histological grade & & & $<0.00$ I \\
\hline Well-differentiated & 57 & 75 & \\
\hline Poorly differentiated & 348 & 198 & \\
\hline Histological type & & & 0.004 \\
\hline Intestinal type & 80 & 68 & \\
\hline Diffuse type & 175 & 75 & \\
\hline Mixed type & 45 & 31 & \\
\hline TNM stage & & & 0.67 \\
\hline I & 84 & 51 & \\
\hline ॥ & 109 & 81 & \\
\hline III & 212 & 141 & \\
\hline Adjuvant chemotherapy & & & 0.54 \\
\hline Yes & 297 & 206 & \\
\hline No & 108 & 67 & \\
\hline CEA & & & 0.06 \\
\hline Normal & 307 & 175 & \\
\hline Elevated & 71 & 59 & \\
\hline CAI9-9 & & & 0.58 \\
\hline Normal & 321 & 190 & \\
\hline Elevated & 44 & 30 & \\
\hline CA72-4 & & & 0.78 \\
\hline Normal & 294 & 176 & \\
\hline Elevated & 74 & 47 & \\
\hline VEGF expression & & & 0.008 \\
\hline Positive & 159 & 80 & \\
\hline Negative & 246 & 193 & \\
\hline
\end{tabular}

Abbreviations: CA, carbohydrate antigen; CEA, carcinoembryonic antigen; HER2, human epidermal growth factor receptor 2; TNM, tumor-node-metastasis; VEGF, vascular endothelial growth factor.

be partly explained by our use of a less stringent definition of HER2 overexpression than that used by others.

In our study, we also found that HER2 expression was associated with male sex, tumor location, well-differentiated histology, intestinal-type pathology, and VEGF expression, and these findings are consistent with previous studies. ${ }^{27,30-32}$ For example, Aizawa et $\mathrm{al}^{27}$ found that HER 2 overexpression was more commonly observed in male patients and patients with well-differentiated tumors. Oh et al ${ }^{30}$ reported that HER2 expression was associated with well- or moderately differentiated and intestinal-type tumors. However, it is perplexing that although HER2 overexpression was associated with shorter OS, it was also associated with well-differentiated histology and intestinal-type pathology, which are both usually associated with more favorable outcomes. The reason for these results is unknown, and we believe further exploration of this finding is warranted.

When we stratified our patients into those who were higher risk and treated with surgery plus adjuvant chemotherapy and those treated with surgery alone, HER 2 expression was associated with shorter survival in patients in the first group, but not in the second. Similarly, Kurokawa et $\mathrm{al}^{32}$ reported that 
Table 3 Prognostic factors for OS in 678 patients with Stage I-III GC undergoing curative resection

\begin{tabular}{|c|c|c|c|c|}
\hline Characteristic & $\begin{array}{l}\text { Univariate analysis } \\
\mathrm{HR}(95 \% \mathrm{Cl})\end{array}$ & $P$-value & $\begin{array}{l}\text { Multivariate analysis } \\
\mathrm{HR}(95 \% \mathrm{Cl})\end{array}$ & $P$-value \\
\hline Age, years & $1.320(0.967-1.802)$ & 0.08 & & \\
\hline \multicolumn{5}{|l|}{$<60$} \\
\hline \multicolumn{5}{|l|}{$\geq 60$} \\
\hline Sex & $1.066(0.767-1.479)$ & 0.71 & & \\
\hline \multicolumn{5}{|l|}{ Male } \\
\hline \multicolumn{5}{|l|}{ Female } \\
\hline Tumor location & $0.799(0.669-0.956)$ & 0.01 & $0.898(0.74|-| .088)$ & 0.27 \\
\hline \multicolumn{5}{|l|}{ Upper third } \\
\hline \multicolumn{5}{|l|}{ Middle third } \\
\hline \multicolumn{5}{|l|}{ Lower third } \\
\hline Tumor size, $\mathrm{cm}$ & $1.780(1.302-2.433)$ & $<0.001$ & $\mathrm{I} .087$ (0.770-I.534) & 0.64 \\
\hline \multicolumn{5}{|l|}{$<5$} \\
\hline \multicolumn{5}{|l|}{$\geq 5$} \\
\hline Histological grade & $1.488(0.963-2.297)$ & 0.07 & & \\
\hline \multicolumn{5}{|l|}{ Well-differentiated } \\
\hline \multicolumn{5}{|l|}{ Poorly differentiated } \\
\hline Histological type & I.043 (0.8I5-I.335) & 0.74 & & \\
\hline \multicolumn{5}{|l|}{ Intestinal type } \\
\hline \multicolumn{5}{|l|}{ Diffuse type } \\
\hline \multicolumn{5}{|l|}{ Mixed type } \\
\hline TNM stage & $3.76 \mathrm{I}(2.704-5.232)$ & $<0.001$ & $3.878(2.665-5.643)$ & $<0.001$ \\
\hline \multicolumn{5}{|l|}{ I } \\
\hline \multicolumn{5}{|l|}{$\|$} \\
\hline \multicolumn{5}{|l|}{ III } \\
\hline Adjuvant chemotherapy & $1.224(0.830-1.803)$ & 0.31 & & \\
\hline \multicolumn{5}{|l|}{ Yes } \\
\hline \multicolumn{5}{|l|}{ No } \\
\hline CEA & $1.668(1.174-2.370)$ & 0.004 & I.I77 (0.808-I.7I5) & 0.40 \\
\hline \multicolumn{5}{|l|}{ Normal } \\
\hline \multicolumn{5}{|l|}{ Elevated } \\
\hline CAI9-9 & $1.736(1.127-2.676)$ & 0.01 & $1.383(0.889-2.15 \mathrm{I})$ & 0.15 \\
\hline \multicolumn{5}{|l|}{ Normal } \\
\hline \multicolumn{5}{|l|}{ Elevated } \\
\hline CA72-4 & $1.216(0.824-1.795)$ & 0.32 & & \\
\hline \multicolumn{5}{|l|}{ Normal } \\
\hline \multicolumn{5}{|l|}{ Elevated } \\
\hline VEGF expression & 1.485 (1.047-2.108) & 0.03 & $1.252(0.862-1.818)$ & 0.24 \\
\hline Positive & & & & \\
\hline Negative & & & & \\
\hline HER2 expression & $1.419(1.033-1.948)$ & 0.03 & $1.554(1.106-2.182)$ & 0.01 \\
\hline Positive & & & & \\
\hline Negative & & & & \\
\hline
\end{tabular}

Abbreviations: CA, carbohydrate antigen; CEA, carcinoembryonic antigen; $\mathrm{Cl}$, confidence interval; GC, gastric cancer; HER2, human epidermal growth factor receptor 2; $\mathrm{HR}$, hazard ratio; OS, overall survival; TNM, tumor-node-metastasis; VEGF, vascular endothelial growth factor.

HER2 expression was associated with significantly shorter survival in patients who received adjuvant chemotherapy for GC. Our results suggest that HER2 expression may be more valuable as a prognostic indicator in higher-risk patients than in lower-risk patients with GC.

Because HER2 expression is associated with a poor prognosis, Bazas et $\mathrm{al}^{33}$ suggested that GC patients with HER2 expression might benefit from alternative treatment in the form of postoperative autovaccinotherapy. Trastuzumab may be another alternative adjuvant therapy for this subset of patients. However, another study, focusing only on advanced GC, reported that HER2 expression was not associated with tumor response in those receiving two chemotherapy regimens (S-1 monotherapy or irinotecan with cisplatin) for residual, recurrent, or metastatic GC. This lack of response argues against using HER2 expression in making decisions about chemotherapy in patients with residual, recurrent, or metastatic disease. ${ }^{34}$

When we stratified our patients by stage, those without HER2 expression and with Stage III GC survived longer 
Table 4 Prognostic factors for OS in 445 patients with Stage II-III GC treated with surgery and adjuvant chemotherapy

\begin{tabular}{|c|c|c|c|c|}
\hline Characteristic & $\begin{array}{l}\text { Univariate analysis } \\
\text { HR }(95 \% \mathrm{Cl})\end{array}$ & $P$-value & $\begin{array}{l}\text { Multivariate analysis } \\
\text { HR }(95 \% \mathrm{Cl})\end{array}$ & $P$-value \\
\hline $\begin{array}{l}\text { Age, years } \\
\quad<60 \\
\geq 60\end{array}$ & $1.159(0.815-1.647)$ & 0.41 & & \\
\hline $\begin{array}{l}\text { Sex } \\
\qquad \text { Male } \\
\text { Female }\end{array}$ & $0.990(0.687-\mid .429)$ & 0.96 & & \\
\hline $\begin{array}{l}\text { Tumor location } \\
\text { Upper third } \\
\text { Middle third } \\
\text { Lower third }\end{array}$ & $0.889(0.724-1.091)$ & 0.26 & & \\
\hline $\begin{array}{l}\text { Tumor size, cm } \\
\qquad 5 \\
\geq 5\end{array}$ & $1.573(1.109-2.233)$ & 0.01 & I.I74 (0.8I3-1.697) & 0.39 \\
\hline $\begin{array}{l}\text { Histological grade } \\
\text { Well-differentiated } \\
\text { Poorly differentiated }\end{array}$ & I.093 (0.67I-I.780) & 0.72 & & \\
\hline $\begin{array}{l}\text { Histological type } \\
\text { Intestinal type } \\
\text { Diffuse type } \\
\text { Mixed type }\end{array}$ & $1.000(0.756-1.324)$ & $>0.99$ & & \\
\hline $\begin{array}{l}\text { TNM stage } \\
\text { II } \\
\text { III }\end{array}$ & $3.850(2.336-6.346)$ & $<0.001$ & $4.076(2.388-6.956)$ & $<0.001$ \\
\hline $\begin{array}{l}\text { CEA } \\
\text { Normal } \\
\text { Elevated }\end{array}$ & $1.595(1.075-2.367)$ & 0.02 & $1.422(0.954-2.120)$ & 0.08 \\
\hline $\begin{array}{l}\text { CAI9-9 } \\
\text { Normal } \\
\text { Elevated }\end{array}$ & $1.398(0.854-2.289)$ & 0.18 & & \\
\hline $\begin{array}{l}\text { CA72-4 } \\
\text { Normal } \\
\text { Elevated }\end{array}$ & I. $104(0.722-1.690)$ & 0.65 & & \\
\hline $\begin{array}{l}\text { VEGF expression } \\
\text { Positive } \\
\text { Negative }\end{array}$ & $1.283(0.872-1.890)$ & 0.21 & & \\
\hline $\begin{array}{l}\text { HER2 expression } \\
\text { Positive } \\
\text { Negative }\end{array}$ & $1.504(1.056-2.14 I)$ & 0.02 & $1.702(1.182-2.45 \mathrm{I})$ & 0.004 \\
\hline
\end{tabular}

Abbreviations: CA, carbohydrate antigen; CEA, carcinoembryonic antigen; Cl, confidence interval; GC, gastric cancer; HER2, human epidermal growth factor receptor 2; $\mathrm{HR}$, hazard ratio; OS, overall survival; TNM, tumor-node-metastasis; VEGF, vascular endothelial growth factor.

after the combination of surgery with adjuvant chemotherapy than did Stage III patients who received surgery alone. We speculate that this may be because patients without HER2 expression may possess more favorable tumor biology, with the potential for a better response to chemotherapy. These results suggest that even those Stage III patients without HER2 expression, who might seem to have a better prognosis than those with HER2 expression, are still likely to benefit from adjuvant chemotherapy.

We also investigated the relationship between VEGF expression and OS. Although multivariate analysis of our data showed that HER2 expression was independently associated with OS in patients with GC, it also showed that
VEGF expression was not independently associated with OS. VEGF is important in vasculogenesis and angiogenesis, and although our study suggests that its expression may not have prognostic value in $\mathrm{GC}$, others have suggested that it does. ${ }^{11}$ Thus, we believe that additional investigation into the prognostic value of VEGF expression in GC is warranted.

HER2 expression can be measured with several methods. The most commonly used methods are FISH, which detects gene amplification by measuring the number of copies of the HER2 gene in the nuclei of tumor cells, and IHC, which measures the number of HER2 receptors on the cell surface and detects receptor overexpression. The accuracy of HER2 testing may be increased by using a combination 

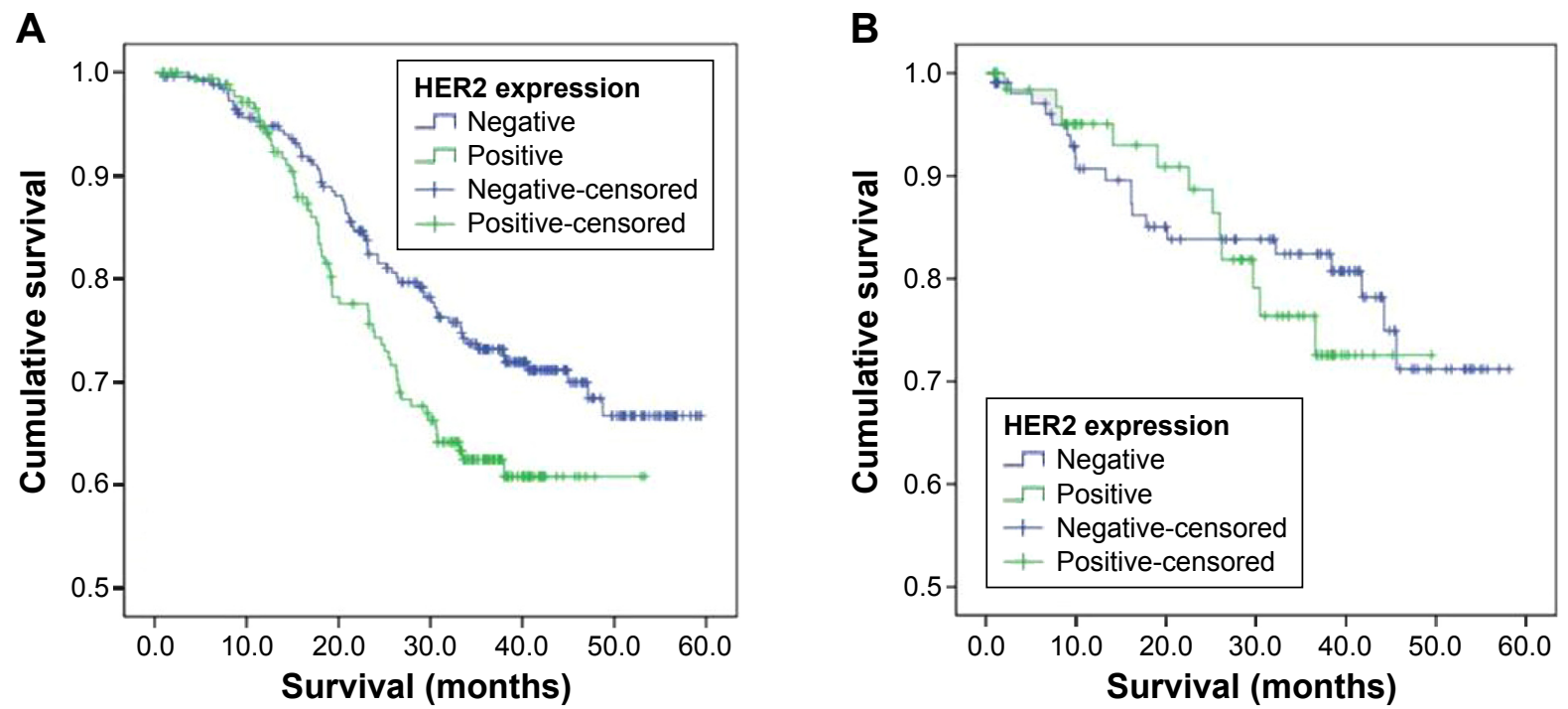

Figure 2 OS based on HER2 immunohistochemical expression in patients with Stage II-III GC (A) treated with surgery and adjuvant chemotherapy and (B) treated with surgery alone.

Abbreviations: OS, overall survival; HER2, human epidermal growth factor receptor 2; GC, gastric cancer.

of assays. ${ }^{35}$ Because IHC appears to be the most commonly used technique in clinical practice, and because FISH requires expensive equipment not widely available in pathology laboratories, we used IHC alone for measuring HER2 and VEGF expression and confirmed its clinical utility.

At present, although many studies have investigated the clinical benefits of HER2-targeted therapy (trastuzumab) in $\mathrm{GC}$, the prognostic value and clinical utility of HER2 expression in determining when to use this agent remain unclear. ${ }^{36}$ With our results in mind, we encourage prospective multicenter-randomized trials involving the measurement of HER2 expression in patients receiving trastuzumab for GC.

Our study has several limitations. It was a singlecenter rather than multicenter investigation. However, one benefit of this arrangement was that surgical procedures, IHC testing, and follow-up evaluations were standardized and consistent during the study period. This consistency was particularly beneficial for IHC testing, because the reliability and comparability of results can be affected by
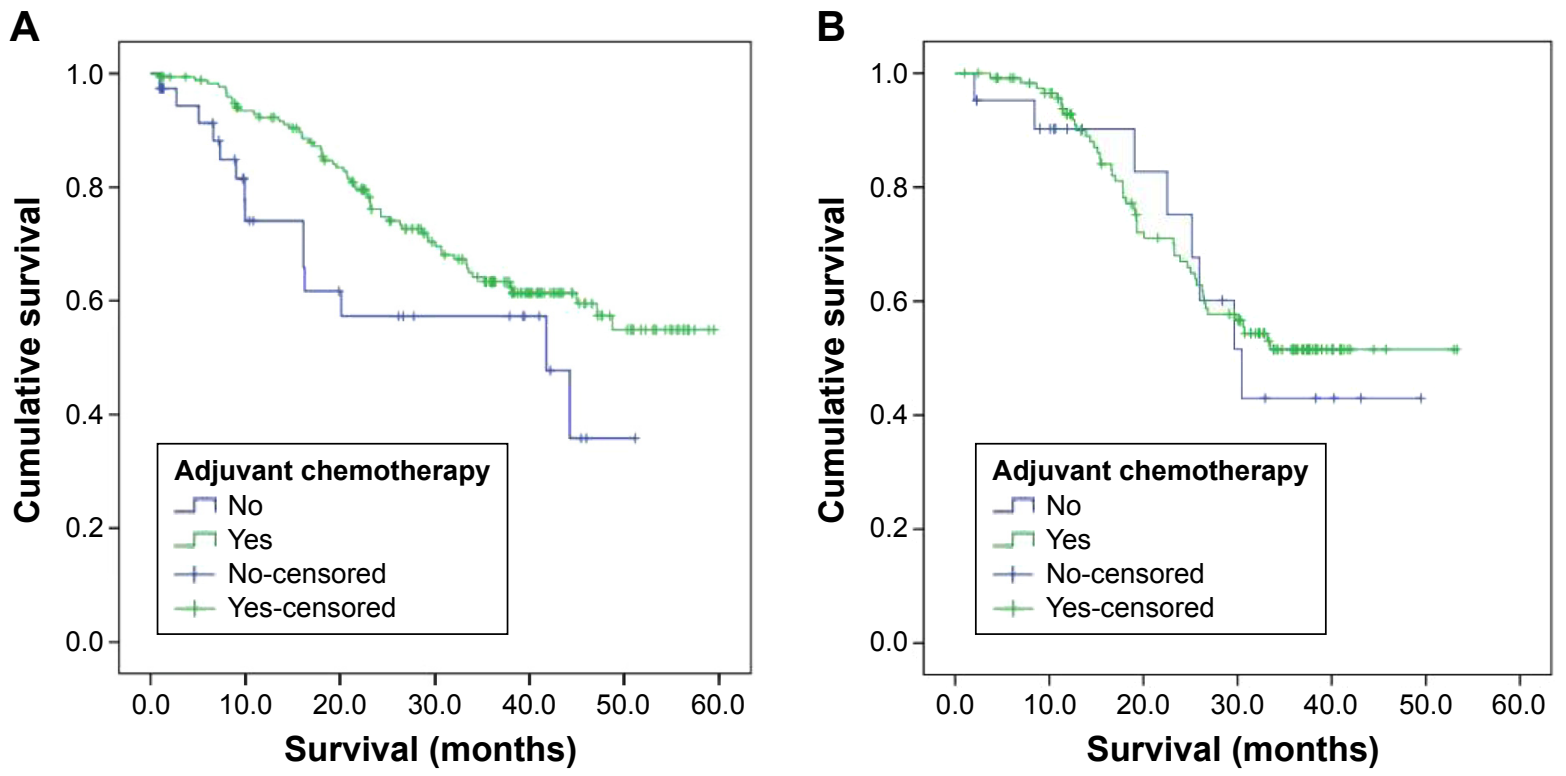

Figure 3 OS based on adjuvant chemotherapy in patients with Stage III GC (A) without HER2 expression and (B) with HER2 expression. Abbreviations: OS, overall survival; GC, gastric cancer; HER2, human epidermal growth factor receptor 2. 
using different primary antibodies and detection methods (including controls), and by nonstandardized, subjective interpretation. ${ }^{35,37}$ Finally, although we used OS as our primary outcome, only $23.5 \%$ of our patients died during the study. Thus, we might have collected data on other survival measures, such as disease-free survival. As a result, we believe our conclusions may need to be validated with additional outcome measures.

\section{Conclusion}

HER2 expression is independently associated with OS in $\mathrm{GC}$, especially in patients who are at higher risk and receive adjuvant chemotherapy after curative resection. HER2 expression may have important clinical utility in directing adjuvant treatment for Stage III GC patients.

\section{Acknowledgment}

The authors thank all the people who helped with this study.

\section{Disclosure}

The authors report no conflicts of interest in this work.

\section{References}

1. Hamashima C. Current issues and future perspectives of gastric cancer screening. World J Gastroenterol. 2014;20(38):13767-13774.

2. Ferlay J, Soerjomataram I, Dikshit R, et al. Cancer incidence and mortality worldwide: sources, methods and major patterns in GLOBOCAN 2012. Int J Cancer. 2015;136(5):E359-E386.

3. Rahman R, Asombang AW, Ibdah JA. Characteristics of gastric cancer in Asia. World J Gastroenterol. 2014;20(16):4483-4490.

4. Thibault C, Khodari W, Lequoy M, Gligorov J, Belkacemi Y. HER2 status for prognosis and prediction of treatment efficacy in adenocarcinomas: a review. Crit Rev Oncol Hematol. 2013;88(1):123-133.

5. Song HS, Do YR, Kim IH, Sohn SS, Kwon KY. Prognostic significance of immunohistochemical expression of EGFR and C-erbB-2 oncoprotein in curatively resected gastric cancer. Cancer Res Treat. 2004; 36(4):240-245.

6. Lee KE, Lee HJ, Kim YH, et al. Prognostic significance of p53, nm23, PCNA and c-erbB-2 in gastric cancer. Jpn J Clin Oncol. 2003;33(4): 173-179.

7. Oshima CT, Lanzoni VP, Iriya K, Forones NM. C-erbB-2 oncoprotein in gastric carcinoma: correlation with clinical stage and prognosis. Int J Biol Markers. 2001;16(4):250-254.

8. Barros-Silva JD, Leitao D, Afonso L, et al. Association of ERBB2 gene status with histopathological parameters and disease-specific survival in gastric carcinoma patients. Br J Cancer. 2009;100(3):487-493.

9. Zhang XL, Yang YS, Xu DP, et al. Comparative study on overexpression of HER2/neu and HER3 in gastric cancer. World J Surg. 2009; 33(10):2112-2118.

10. Lv J, Yao YS, Zhou F, et al. Prognosis significance of HER2 status and TACC1 expression in patients with gastric carcinoma. Med Oncol. 2014;31(11):280.

11. Peng L, Zhan P, Zhou Y, et al. Prognostic significance of vascular endothelial growth factor immunohistochemical expression in gastric cancer: a meta-analysis. Mol Biol Rep. 2012;39(10):9473-9484.

12. Washington $\mathrm{K}$. 7th edition of the AJCC cancer staging manual: stomach. Ann Surg Oncol. 2010;17(12):3077-3079.
13. Murad AM, Santiago FF, Petroianu A, Rocha PR, Rodrigues MA, Rausch M. Modified therapy with 5-fluorouracil, doxorubicin, and methotrexate in advanced gastric cancer. Cancer. 1993;72(1):37-41.

14. Paoletti X, Oba K, Burzykowski T, et al. Benefit of adjuvant chemotherapy for resectable gastric cancer: a meta-analysis. JAMA. 2010; 303(17):1729-1737.

15. Moertel CG, Childs DS, O'Fallon JR, Holbrook MA, Schutt AJ, Reitemeier RJ. Combined 5-fluorouracil and radiation therapy as a surgical adjuvant for poor prognosis gastric carcinoma. J Clin Oncol. 1984;2(11):1249-1254.

16. Bang YJ, Van Cutsem E, Feyereislova A, et al. Trastuzumab in combination with chemotherapy versus chemotherapy alone for treatment of HER2-positive advanced gastric or gastro-oesophageal junction cancer (ToGA): a phase 3, open-label, randomised controlled trial. Lancet. 2010;376(9742):687-697.

17. Potrc S, Gadiijev E, Hajdinjak T, Kavalar R. Clinicopathological and immunohistochemical markers after radical gastrectomy for gastric cancer. Hepatogastroenterology. 2007;54(73):308-314.

18. Kubicka S, Claas C, Staab S, et al. p53 mutation pattern and expression of c-erbB2 and c-met in gastric cancer: relation to histological subtypes, Helicobacter pylori infection, and prognosis. Dig Dis Sci. 2002; 47(1):114-121.

19. Hedayatizadeh-Omran A, Rafiei A, Alizadeh-Navaei R, et al. Role of HER2 in brain metastasis of breast cancer: a systematic review and meta-analysis. Asian Pac J Cancer Prev. 2015;16(4):1431-1434.

20. Son HS, Shin YM, Park KK, et al. Correlation between HER2 overexpression and clinicopathological characteristics in gastric cancer patients who have undergone curative resection. J Gastric Cancer. 2014; 14(3):180-186.

21. Park DI, Yun JW, Park JH, et al. HER-2/neu amplification is an independent prognostic factor in gastric cancer. Dig Dis Sci. 2006;51(8) 1371-1379.

22. Hsu JT, Chen TC, Tseng JH, et al. Impact of HER-2 overexpression/ amplification on the prognosis of gastric cancer patients undergoing resection: a single-center study of 1,036 patients. Oncologist. 2011;16(12): $1706-1713$.

23. Tang D, Liu CY, Shen D, et al. Assessment and prognostic analysis of EGFR, HER2, and HER3 protein expression in surgically resected gastric adenocarcinomas. Onco Targets Ther. 2015;8:7-14.

24. Gu J, Zheng L, Zhang L, et al. TFF3 and HER2 expression and their correlation with survival in gastric cancer. Tumour Biol. 2015; 36(4):3001-3007.

25. Wang S, Zheng G, Chen L, Xiong B. Effect of HER-2/neu overexpression on prognosis in gastric cancer: a meta-analysis. Asian Pac $J$ Cancer Prev. 2011;12(6):1417-1423.

26. Chua TC, Merrett ND. Clinicopathologic factors associated with HER2-positive gastric cancer and its impact on survival outcomes - a systematic review. Int J Cancer. 2012;130(12):2845-2856.

27. Aizawa M, Nagatsuma AK, Kitada K, et al. Evaluation of HER2-based biology in 1,006 cases of gastric cancer in a Japanese population. Gastric Cancer. 2014;17(1):34-42.

28. Xu CC, Yue L, Wei HJ, et al. Significance of TFF3 protein and Her-2/ neu status in patients with gastric adenocarcinoma. Pathol Res Pract. 2013;209(8):479-485.

29. Qiu M, Zhou Y, Zhang X, et al. Lauren classification combined with HER2 status is a better prognostic factor in Chinese gastric cancer patients. BMC Cancer. 2014;14:823.

30. Oh HS, Eom DW, Kang GH, et al. Prognostic implications of EGFR and HER-2 alteration assessed by immunohistochemistry and silver in situ hybridization in gastric cancer patients following curative resection. Gastric Cancer. 2014;17(3):402-411.

31. De Carli DM, Rocha MP, Antunes LC, et al. Immunohistochemical expression of HER2 in adenocarcinoma of the stomach. Arq Gastroenterol. 2015;52(2):152-155.

32. Kurokawa Y, Matsuura N, Kimura Y, et al. Multicenter large-scale study of prognostic impact of HER2 expression in patients with resectable gastric cancer. Gastric Cancer. 2015;18(4):691-697. 
33. Bazas VM, Lukyanova NY, Lisovenko GS, Rozumiy DO, Potebnya GP. Postoperative autovaccinotherapy for patients with gastric cancer and expression of some proteins in tumor tissue. Exp Oncol. 2009;31(3): $182-184$.

34. Matsubara J, Hirashima Y, Yamada Y. [Impact of HER2, EGFR, IGF-1R, and VEGFR expressions on the outcome of chemotherapy for advanced gastric cancer]. Gan To Kagaku Ryoho. 2010;37(8):1489-1496. Japanese.

35. Yano T, Doi T, Ohtsu A, et al. Comparison of HER2 gene amplification assessed by fluorescence in situ hybridization and HER2 protein expression assessed by immunohistochemistry in gastric cancer. Oncol Rep. 2006;15(1):65-71.
36. Rose JS, Bekaii-Saab TS. New developments in the treatment of metastatic gastric cancer: focus on trastuzumab. Onco Targets Ther. 2011;4:21-26.

37. Sheng WQ, Huang D, Ying JM, et al. HER2 status in gastric cancers: a retrospective analysis from four Chinese representative clinical centers and assessment of its prognostic significance. Ann Oncol. $2013 ; 24(9): 2360-2364$.

\section{Publish your work in this journal}

OncoTargets and Therapy is an international, peer-reviewed, open access journal focusing on the pathological basis of all cancers, potential targets for therapy and treatment protocols employed to improve the management of cancer patients. The journal also focuses on the impact of management programs and new therapeutic agents and protocols on

\section{Dovepress}

patient perspectives such as quality of life, adherence and satisfaction. The manuscript management system is completely online and includes a very quick and fair peer-review system, which is all easy to use. Visit http://www.dovepress.com/testimonials.php to read real quotes from published authors.

Submit your manuscript here: http://www.dovepress.com/oncotargets-and-therapy-journal 